National Health and Welfare. We thank Drs L. S. Harris and P. Munson for facilities at North Carolina University.

P. D. COOPER

Section of Biochemical Pharmacology,

Faculty of Pharmacy,

University of Montreal

G. C. Walters

Department of Psychology,

University of Toronto

Received December 23, 1971; revised February 14, 1972.

${ }^{1}$ Chothia, C., and Pauling, P., Proc. US Nat. Acad. Sci., 63, 1063 (1969).

${ }^{2}$ Snyder, S. H., and Richelson, E., Proc. US Nat. Acad. Sci., 60, 206 (1968).

${ }^{3}$ Kang, S., and Green, J. P., Proc. US Nat. Acad. Sci., 67, 62 (1970).

${ }^{4}$ Neville, G. A., Deslauriers, R., Blackburn, B. J., and Smith, I. C. P., J. Med. Chem., 14, 717 (1971).

5 Bailey, K., J. Pharm. Sci., 60, 1232 (1971).

6 Walters, G. C., and Cooper, P. D., Nature, 218, 298 (1968).

7 Cooper, P. D., Canad. J. Chem., 48, 3882 (1970).

8 Zimmerman, J., and Schuster, C. R., J. Exp. Anal. Behav., 5, 497 (1962)

9 Smythies, J. R., Johnston, V. S., and Bradley, R. J., Brit. J. Psychiat., 115, 55 (1969).

10 Webster, C. D., Walters, G. C., and Willinsky, M. D., Nature (in the press).

1 Sarkar, S., Banerjee, R., Ise, M. S., and Zeller, E. A., Helv. Chim. Acta, 43, 439 (1960).

12 Costa, E., The Pharmacologist, 1, 82 (1969).

13 Tedeschi, D. H., Tedeschi, R. E., and Fellows, E. J., Proc. Soc. Exp. Biol. Med., 103, 680 (1960).

\section{Keratoblast and Keratocyte, not Keratinocyte}

Cells of both the reproductive and functional compartments of oral and cutaneous epithelia are at present indiscriminately called "keratinocytes". The two types of cells, however, differ markedly in function and fate, and it is therefore logical, as well as useful, to distinguish them by different terms. It is therefore proposed to introduce the term "keratoblast" to denote a cell in the reproductive compartment of these tissues, and thus to distinguish dividing cells from those that produce keratin.

The principal cellular components of oral and cutaneous epithelia fall conveniently into two compartments, namely a proliferative or reproductive compartment and a functional or mature compartment. The cells of the proliferative compartment, found chiefly in the basal cell layer, are reproductive and end by mitotic division. The cells of the functional compartment, found chiefly in the spinous, granular and cornified cells layers, produce keratin and later die and desquamate. The proliferative compartment, having retained its reproductive capacity, constitutes the germinative population for the functional compartment.

The difference between these two types of cells is important enough to warrant a separate name for each, and there are precedents for a semantic distinction between mature and immature cells-for example, chondroblast and chondrocyte, fibroblast and fibrocyte, osteoblast and osteocyte.

"Keratoblast" is the logical name for a reproductive cell of oral and cutaneous epithelia. It connotes "progenitor of keratocyte" and is preferred to "keratinoblast", which is not a well formed word. The Greek word from which these words are derived is "keratos", meaning "horn", and the stem is "kerato-", not "keratino-"1.

The term "keratinocyte", unfortunately, is not accurate. The proper form, as explained in the preceding paragraph, is "keratocyte". There is an analogy here with the closely related melanin-producing cells which are correctly termed "melanocytes" rather than "melaninocytes". It should be mertioned also that "keratinize" and its derivatives, "keratinized" and "keratinization" are not correct, the proper forms being "keratize", "keratized" and "keratization" respectively.

Neither "keratinocyte" nor the other words improperly formed with "keratino-" have yet been included in either Nomina Anatomica or Nomina Histologica; therefore it is to be hoped that "keratocyte" and the other words properly formed with "kerato-" will be generally accepted as the preferred terms.

Department of Restorative Dentistry,

A. IAn Hamilton

School of Dentistry,

University of Washington,

Seattle, Washington 98195

Received February 14; revised March 2, 1972.

1 Roberts, F., Medical Terms, fourth ed. (Heinemann, London, 1966).

\section{Effect of PABA on Chloroquine Resistance in Plasmodium berghei yoelii}

IN mice ${ }^{1}$ paraaminobenzoic acid (PABA) in the diet of the host is necessary for the growth of blood infections of Plasmodium berghei. The area of the parasite metabolism in which PABA is involved is believed to be closely associated with the point of action of certain antimalarial drugs including pyrimethamine, proguanil and the sulphonamides. Several drugs of this group are antagonized by $\mathrm{PABA}^{2}$. The effect of PABA on the antimalarial action of chloroquine has received little attention as chloroquine does not seem to act directly on the pathways of PABA metabolism. Kirakosyan ${ }^{3}$, however, has shown that chloroquine is more effective against a sensitive strain of $P$. berghei berghei in mice when PABA is absent from the diet of the host.

I have examined the effect of different dietary concentrations of PABA on the degree of chloroquine resistance of strains of $P$. berghei yoelii. All strains of $P . b$. yoelii show resistance to the drug $^{4}$, but results from different laboratories on the degree of resistance are sometimes inconsistent. The present results provide a probable explanation for these discrepancies.

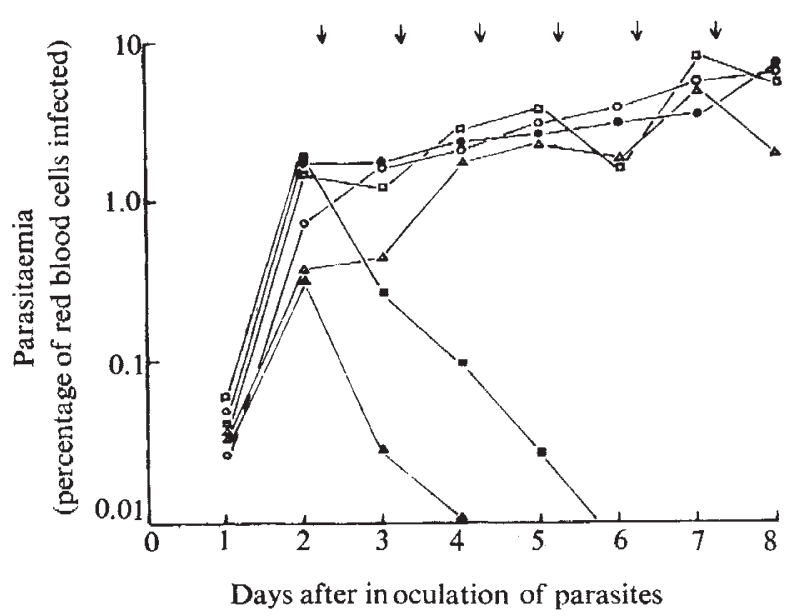

Fig. 1 The effect of different dietary concentrations of PABA on the response to chloroquine of blood infections of $P . b$. yoelii (strain 33X). Each point represents the average parasitaemia of five mice., $5 \times 10^{-3} \mathrm{~g}$ PABA per $100 \mathrm{ml}$. in drinking water; $2.5 \times 10^{-3} \mathrm{~g}$ PABA per $100 \mathrm{ml}$. in drinking water; water; $1.25 \times 10^{-3} \mathrm{~g} \mathrm{PABA}$ per $100 \mathrm{ml}$. in drinking water; 40 mg chloroquine per $\mathrm{kg}$ mouse weight administered; $O \square \Delta$, distilled water administered; $\downarrow$, time at which chloroquine or distilled water was administered. 